\title{
Aplicação de análise textual em publicações relacionadas ao Ensino de Matemática em Ambientes Virtuais de Aprendizagem: Um Mapeamento Sistemático
}

\author{
Gabriel Muller Konflanz, UNIPAMPA, gabriel.konflanz.7@gmail.com \\ https://orcid.org/0000-0002-3507-2026 \\ Vera Lúcia Duarte Ferreira, UNIPAMPA, veraferreira@unipampa.edu.br \\ https://orcid.org/0000-0002-6968-5664 \\ Cristiano Corrêa Ferreira, UNIPAMPA, cristianoferreira@unipampa.edu.br \\ https://orcid.org/0000-0002-7676-9233
}

Resumo: O presente artigo apresenta um Mapeamento Sistemático da Literatura sobre o Ensino de Matemática em Ambientes Virtuais de Aprendizagem, em que se buscou identificar o que já foi proposto, em quais contextos se deram as pesquisas nessa área, quais as tecnologias digitais utilizadas, bem como as abordagens metodológicas, num recorte temporal de 2016 a 2020. O método utilizado na análise das publicações selecionadas fundamentou-se na Análise Textual Discursiva com o apoio do software IRaMuTeQ para o tratamento dos dados. Os resultados indicam que as tecnologias e as metodologias utilizadas evidenciam o movimento dos pesquisadores e professores por buscar novos métodos de ensino para esses espaços de aprendizagem. Por fim, foi observado um déficit de trabalhos que propusessem uma análise comparativa entre contextos e metodologias.

Palavras-chave: ensino de matemática, ambiente virtual de aprendizagem, tecnologias digitais, mapeamento sistemático, análise textual.

\section{Applying textual analysis to publications related to Mathematics Teaching in Virtual Learning Environments: A Systematic Mapping}

Abstract: This paper presents a Systematic Mapping of the Literature on Teaching Mathematics in Virtual Learning Environments, in which we sought to identify what has already been proposed, in which contexts the researches in this field took place, which digital technologies were used, as well as the methodological approaches that were employed, on a time frame of publications from 2016 to 2020. The method used in the analysis of the selected publications was based on Textual Discourse Analysis with the support of the software IRaMuTeQ for data processing. The results show that the technologies and methodologies used evidence the movement of researchers and teachers to seek new teaching methods for these learning spaces. Lastly, a deficit of studies that propose a comparative analysis between contexts and methodologies was observed.

Keywords: teaching of mathematics, virtual learning environment, digital technologies, systematic mapping, textual analysis.

\section{Introdução}

A crescente discussão sobre a utilização de tecnologias digitais no processo de ensino-aprendizagem nos levam a pensar sobre metodologias que incorporam recursos digitais na disseminação do conhecimento, em especial em Ambientes Virtuais de Aprendizagem (AVA), como enfatizam as pesquisas de (CHICON; PASCHOAL; FRANTZ, 2020).

No entanto, é preciso enfatizar que a inserção das tecnologias digitais como recurso de mediação do processo ensino aprendizagem não tem por finalidade substituir métodos ou práticas pedagógicas já utilizadas por professores em suas salas 
de aula, corroborando com Dickel e Notare (2018) quando pontuam que a simples utilização de recursos computacionais não assegura o fazer matemático do aluno.

Os Parâmetros Curriculares Nacionais destacam que a inserção de novas tecnologias devem proporcionar ambientes de aprendizagem que favoreçam a problematização, reflexão e criticidade, bem como a autonomia por parte dos aprendizes (BRASIL, 2002). Em especial, em se tratando de formação de professores, a integração de recursos de tecnologias digitais às práticas pedagógicas oportuniza ao docente assumir a posição de mediador pedagógico em seu pleno sentido, mediando e facilitando a aprendizagem (AMARAL; SABOTA, 2017).

Nessa perspectiva, o objetivo desta pesquisa é identificar em trabalhos publicados no período de 2016 a 2020, a existência de estudos primários sobre o ensino de Matemática em um AVA com a utilização de tecnologias digitais. Este artigo está organizado em mais três seções, as quais apresentam os materiais e métodos, resultados e discussões e as considerações finais da pesquisa.

\section{Materiais e Métodos}

Para a seleção dos trabalhos que foram analisados nesta pesquisa, foi realizado um mapeamento sistemático como método de revisão de literatura, atendendo determinadas diretrizes e tendo como propósito fornecer uma visão abrangente do campo de pesquisa deste trabalho (KITCHENHAM et al., 2007). Nesse sentido, as etapas do protocolo de busca sugeridas por Costa e Zoltowski (2014) são apresentadas na Figura 1.

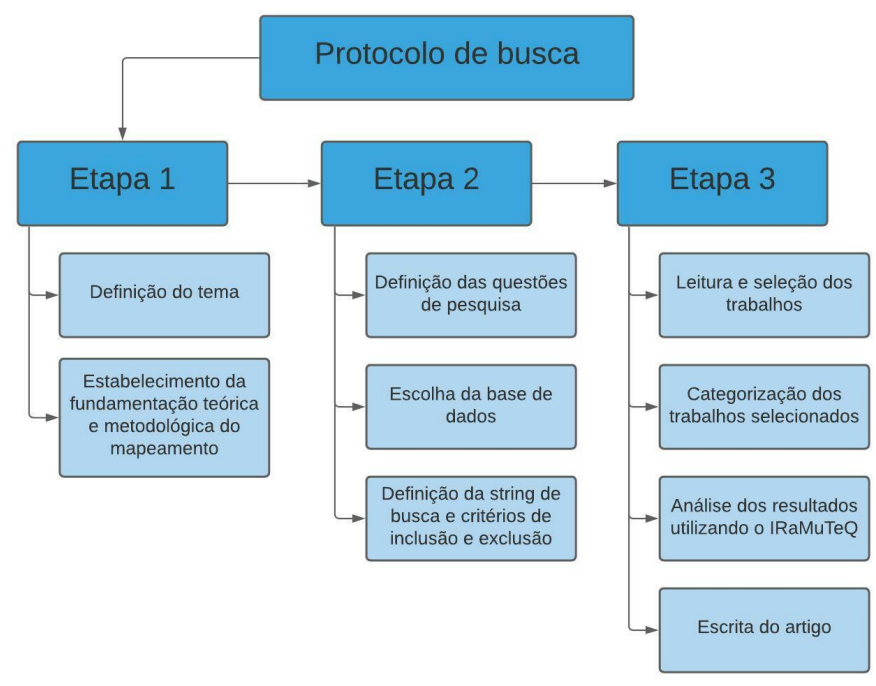

Figura 1 - Etapas do protocolo de busca.

Fonte: Elaborado pelos autores (2021)

Na primeira etapa, foi definido como tema da pesquisa o ensino de Matemática por intermédio de tecnologias digitais com a utilização de um AVA. Na sequência, foi fundamentada a metodologia, o mapeamento sistemático como forma de revisão da literatura, por este ser abrangente e fornecer um panorama geral sobre o tema.

$\mathrm{Na}$ etapa dois, foram definidas três questões de pesquisa específicas (QP1, QP2 e QP3) corroborando com o objetivo estabelecido neste trabalho. QP1: Qual o propósito dos trabalhos de Ensino de Matemática desenvolvidos em AVAs com auxílio tecnologias digitais? QP2: Quais as tecnologias digitais utilizadas? QP3: Quais as metodologias adotadas? Para este mapeamento foi escolhida as produções acadêmicas disponibilizadas na Base Digital de Teses e Dissertações (BDTD). 
Para a organização do string de busca utilizou-se o operador booleano AND e os termos chaves ambiente virtual de aprendizagem, matemática, tecnologias digitais e ensino de matemática. Desse modo, os strings foram dispostos da seguinte forma: "ambiente virtual de aprendizagem AND matemática" e "tecnologias digitais AND ensino de matemática".

$\mathrm{Na}$ etapa três, a seleção das publicações (dissertações e teses) que constituem o escopo deste mapeamento, foi realizada segundo os critérios de inclusão e exclusão que são descritos no Quadro 1. Para que fossem selecionados, os trabalhos deveriam atender simultaneamente aos seis critérios de inclusão (CI). Já aqueles que se enquadraram em ao menos um dos critérios de exclusão (CE), foram descartados.

Quadro 1 - Critérios de Inclusão e Exclusão

\begin{tabular}{|c|c|c|}
\hline Critérios & Inclusão - CI & Exclusão - CE \\
\hline 1. Ano de publicação & $\begin{array}{l}\text { Trabalhos publicados entre } 2016 \text { e } \\
2020\end{array}$ & $\begin{array}{l}\text { Trabalhos publicados antes desse } \\
\text { período }\end{array}$ \\
\hline 2. Idioma & Trabalhos publicados em Português & $\begin{array}{l}\text { Trabalhos publicados em demais } \\
\text { idiomas }\end{array}$ \\
\hline 3. Tipo de publicação & $\begin{array}{l}\text { Publicações feitas em formato de tese } \\
\text { ou dissertação de acesso livre }\end{array}$ & $\begin{array}{l}\text { Demais tipos de trabalhos: resumo } \\
\text { simples, resumo estendido, trabalhos } \\
\text { publicados em anais de eventos e } \\
\text { artigos, de acesso livre ou não }\end{array}$ \\
\hline 4. Termos de busca & $\begin{array}{l}\text { Pesquisas que contenham os termos de } \\
\text { busca no título e/ou nas } \\
\text { palavras-chave }\end{array}$ & $\begin{array}{l}\text { Pesquisas que contenham termos de } \\
\text { busca contidos somente no corpo do } \\
\text { texto }\end{array}$ \\
\hline 5. Assunto & $\begin{array}{l}\text { Tratam de ambientes virtuais de } \\
\text { aprendizagem para ensino de } \\
\text { Matemática }\end{array}$ & $\begin{array}{l}\text { Pesquisas que se apresentam como } \\
\text { um manual de conteúdos de } \\
\text { Matemática }\end{array}$ \\
\hline 6. Metodologia & $\begin{array}{l}\text { Discutem metodologias, recursos e } \\
\text { teorias de aprendizagem que fazem } \\
\text { uso de TIC para o ensino de } \\
\text { matemática }\end{array}$ & $\begin{array}{l}\text { Discutem questões ligadas apenas a } \\
\text { aprendizagem da matemática }\end{array}$ \\
\hline
\end{tabular}

Fonte: Elaborado pelos autores (2021)

A partir do protocolo de busca, foram encontradas inicialmente 610 produções. A primeira triagem consistiu na leitura do título, palavras-chave e resumos dos trabalhos, na segunda foi realizada a aplicação dos critérios de inclusão e exclusão. Após todas as etapas de triagem das produções acadêmicas encontradas foram selecionados 20 trabalhos. O Quadro 2 apresenta de forma simplificada os trabalhos selecionados.

Quadro 2 - Publicações selecionadas no mapeamento.

\begin{tabular}{|l|l|}
\hline [código do trabalho] Autor & \multicolumn{1}{c|}{ Título } \\
\hline $\begin{array}{l}\text { [T01] REINHEIMER, } \\
\text { Morgana Aline }\end{array}$ & $\begin{array}{l}\text { Do coletivo ao individual e vice-versa: uma experiência de trabalho } \\
\text { coletivo no uso combinado de diferentes Espaços Virtuais na formação } \\
\text { continuada de professores de matemática. }\end{array}$ \\
\hline $\begin{array}{l}\text { [T02] MALTA, Valcineide } \\
\text { dos Santos }\end{array}$ & $\begin{array}{l}\text { O ensino de progressões sob a abordagem de uma aprendizagem } \\
\text { cooperativa mediada pelo classroom. }\end{array}$ \\
\hline [T03] AMARAL, Joarez José & Gamificação como proposta para o engajamento de alunos em MOOC \\
\hline
\end{tabular}




\begin{tabular}{|c|c|}
\hline Leal do & $\begin{array}{l}\text { sobre educação financeira escolar: possibilidades e desafios para a } \\
\text { educação matemática. }\end{array}$ \\
\hline $\begin{array}{l}\text { [T04] CALHEIROS, Kéliton } \\
\text { José da Matta }\end{array}$ & $\begin{array}{l}\text { Colaboração na metodologia da Sala de aula invertida: apoiando a } \\
\text { comunicação no ensino de geometria. }\end{array}$ \\
\hline $\begin{array}{l}\text { [T05] CERON, Camila } \\
\text { Garbelini da Silva }\end{array}$ & $\begin{array}{l}\text { O pensamento funcional nos anos iniciais em aulas de matemática na } \\
\text { perspectiva do ensino híbrido. }\end{array}$ \\
\hline $\begin{array}{l}\text { [T06] TENÓRIO, Marcos } \\
\text { Mincov }\end{array}$ & $\begin{array}{l}\text { Ambiente virtual de aprendizagem baseado em gamificação: um estudo } \\
\text { de caso em probabilidade e estatística. }\end{array}$ \\
\hline $\begin{array}{l}\text { [T07] SILVA, Anselmo Luís } \\
\text { Corrêa da }\end{array}$ & O ensino do cilindro e da pirâmide através da sala de aula invertida. \\
\hline $\begin{array}{l}\text { [T08] SANTOS, Neylane } \\
\text { Lobato dos }\end{array}$ & Sala invertida: um experimento no ensino de matemática. \\
\hline $\begin{array}{l}\text { [T09] SASSI, Sabrina } \\
\text { Bourscheid }\end{array}$ & $\begin{array}{l}\text { O ambiente virtual de aprendizagem como apoio ao ensino presencial } \\
\text { de matemática: uma proposta com design instrucional. }\end{array}$ \\
\hline $\begin{array}{l}\text { [T10] SAIOL, Meiriele } \\
\text { Nonato de Oliveira }\end{array}$ & $\begin{array}{l}\text { Chat e educação financeira escolar: investigando interações em um } \\
\text { ambiente virtual de aprendizagem. }\end{array}$ \\
\hline [T11] BOTH, Mateus & $\begin{array}{l}\text { Relações entre grandezas geométricas: um estudo de caso baseado na } \\
\text { aprendizagem significativa e análise de erros. }\end{array}$ \\
\hline $\begin{array}{l}\text { [T12] PEREIRA, Geraldo } \\
\text { Henrique Alves }\end{array}$ & $\begin{array}{l}\text { Geometria interativa: novas mídias numa proposta metodológica para o } \\
\text { ensino médio. }\end{array}$ \\
\hline $\begin{array}{l}\text { [T13] FELCHER, Carla } \\
\text { Denize Ott }\end{array}$ & $\begin{array}{l}\text { Tecnologias Digitais e Ensino de Matemática: O uso de Facebook no } \\
\text { processo de ensino dos números racionais. }\end{array}$ \\
\hline $\begin{array}{l}\text { [T14] XOTESLEM, Wesley } \\
\text { Vieira }\end{array}$ & $\begin{array}{l}\text { Personalização do ensino de matemática na perspectiva do ensino } \\
\text { híbrido. }\end{array}$ \\
\hline $\begin{array}{l}\text { [T15] TOMAZI, Débora } \\
\text { Regina }\end{array}$ & $\begin{array}{l}\text { A plataforma Khan Academy para o ensino de matemática do } 4^{\circ} \text { ano do } \\
\text { ensino fundamental: aspectos teóricos e práticos. }\end{array}$ \\
\hline $\begin{array}{l}\text { [T16] SOUZA, Paulo César } \\
\text { Tavares de }\end{array}$ & Materiais manipuláveis e recursos digitais no ensino de trigonometria. \\
\hline $\begin{array}{l}\text { [T17] ROMANELLO, Laís } \\
\text { Aparecida }\end{array}$ & $\begin{array}{l}\text { Potencialidades do uso do celular na sala de aula: atividades } \\
\text { investigativas para o ensino de função. }\end{array}$ \\
\hline $\begin{array}{l}\text { [T18] FERREIRA, Esmênia } \\
\text { Furtado Parreira }\end{array}$ & $\begin{array}{l}\text { A integração das tecnologias digitais ao ensino e aprendizagem de } \\
\text { geometria no ensino fundamental - anos finais: uma proposta com foco } \\
\text { no estudo de perímetro e área de figuras geométricas planas. }\end{array}$ \\
\hline $\begin{array}{l}\text { [T19] COELHO, Janaina } \\
\text { Aparecida Ponté }\end{array}$ & $\begin{array}{l}\text { Uso de gamificação em cursos online abertos e massivos para formação } \\
\text { continuada de docentes de matemática. }\end{array}$ \\
\hline $\begin{array}{l}\text { [T20] SOUZA, Liliane de } \\
\text { Oliveira }\end{array}$ & $\begin{array}{l}\text { As TIC na formação docente: fundamentos para o design de objetos } \\
\text { virtuais de aprendizagem. }\end{array}$ \\
\hline
\end{tabular}

Fonte: Elaborado pelos autores (2021)

A lista completa com os dados extraídos e os links para acesso individual dos trabalhos, pode ser acessado em: $\mathbb{E}$ Extração de dados mapeamento

A etapa final do mapeamento sistemático configurou-se na análise das publicações selecionadas. Para tal, foi utilizado os pressupostos da Análise Textual V. $19 \mathrm{~N}^{\circ}$ 2, Dezembro, 2021 DOI: https://doi.org/10.22456/1679-1916.121203 RENOTE 
Discursiva (ATD) proposto por Moraes e Galiazzi (2016), que corresponde a uma metodologia de análise de informações de natureza qualitativa com a finalidade de produzir novas compreensões sobre os fenômenos.

A ATD é uma abordagem de análise organizada em três estágios: unitarização, onde ocorre a desmontagem dos textos e a separação em unidades de significados; categorização, estabelecendo relações entre as unidades de significado semelhantes; interpretação, processo onde a imersão focalizada pelos dois primeiros estágios gera meta-textos analíticos que compõem os textos interpretativos (MORAES; GALIAZZI, 2006).

No intuito de categorizar as publicações selecionadas via levantamento de similaridades, gerou-se um corpus textual analisado com o auxílio software livre IRaMuTeQ (RATINAUD, 2012). Nessa ferramenta computacional, a análise de similitude está alicerçada na teoria de grafos para obter a identificação de coocorrências entre as palavras, trazendo indicações da conexidade entre as palavras do corpus textual. No entanto, no que tange a representação gráfica é preciso ater-se à forma, quantidade e espessura das ligações entre as formas ativas (palavras mais frequentes) visto que evidenciam maior ou menor conexidade, corroborando com Teixeira (2020) quando enfatiza que o grau de conexão oportuniza fazer inferência sobre a estrutura de construção do texto, bem como dos temas tratados nas pesquisa. Vale ressaltar que, a categorização constitui um processo de comparação constante que resulta no agrupamento de elementos semelhantes. Nesse sentido, os conjuntos que contêm elementos com significados próximos constituem as categorias (MORAES, 2003).

\section{Resultados e Discussão}

Esta seção apresenta uma visão geral das produções que foram selecionadas nas etapas de extração e triagem apresentadas na Seção 2. Na sequência, serão descritos e discutidos os resultados, em detalhes, relacionados às questões de pesquisa que norteiam este mapeamento.

Os 20 trabalhos selecionados para o mapeamento sistemático são do período entre 2016 e 2020, onde 6 trabalhos são de 2016 [T09, T11, T12, T17, T18, T20], 4 de 2017 [T10, T13, T15, T19], 2 de 2018 [T14, T16], 7 de 2019 [T02, T03, T04, T05, T06, T07, T08] e 1 de 2020 [T01]. Desses trabalhos, 19 são dissertações de mestrado e uma tese de doutorado. A Figura 2 mostra a distribuição dos trabalhos por região do Brasil, na qual a região sudeste representa $40 \%$ dos trabalhos selecionados, $30 \%$ da região sul, $15 \%$ da região centro-oeste e $15 \%$ da região norte.

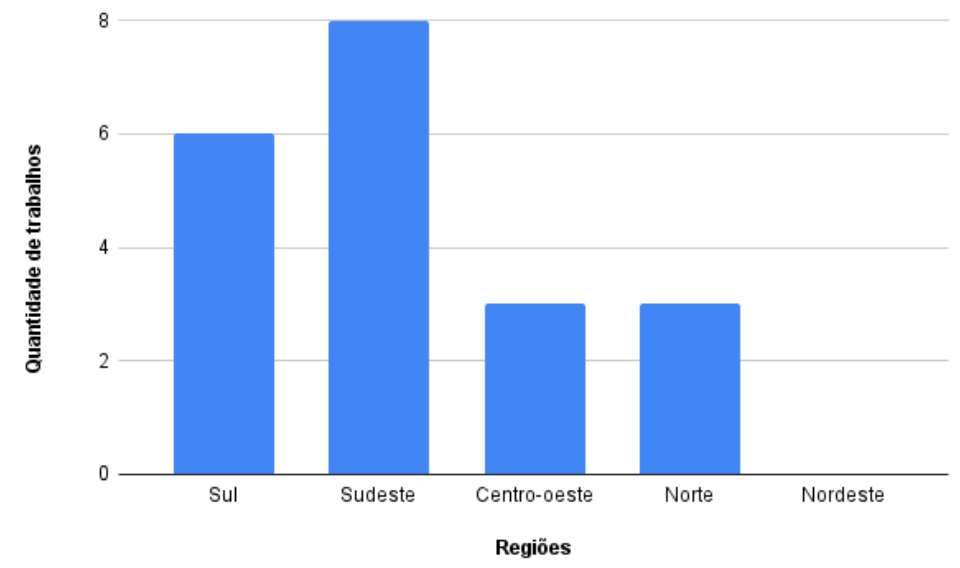

Figura 2 - Distribuição dos trabalhos por regiões do Brasil. Fonte: Elaborado pelos autores (2021) 
QP1: O que está sendo proposto nos trabalhos acadêmicos, em relação ao desenvolvimento de ambientes virtuais de aprendizagem para o ensino de Matemática com utilização de tecnologias digitais?

Para identificar as estratégias de implementação de um AVA para ensino de Matemática que utilizem tecnologias digitais encontradas nas produções resultantes deste mapeamento sistemático foram definidas categorias classificatórias. Os trabalhos foram categorizados quanto ao contexto e os resultados, de forma livre pelo pesquisador, como sugere a ATD.

Os estudos foram classificados seguindo as categorias de desenvolvimento das pesquisas no Ensino Fundamental [T04, T05, T10, T13, T15, T17, T18], Ensino Médio [T02, T03, T07, T08, T09, T12, T14], Ensino Superior [T06, T11, T19, T20] e Formação Continuada [T01, T16]. Compuseram o corpus textual analisado: os objetivos, o contexto, bem como os resultados das pesquisas, identificando as estratégias definidas pelos autores para responder a Questão de Pesquisa 1.

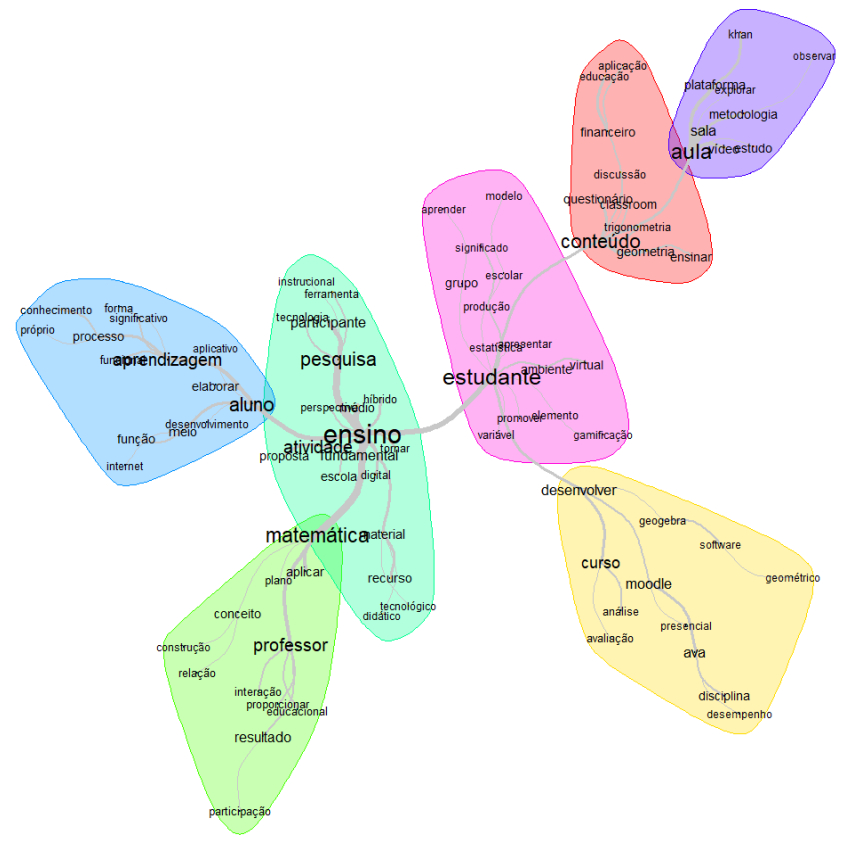

Figura 3 - Análise de Similitude obtida no IRaMuTeQ: objetivos, contexto e resultados dos trabalhos.

Fonte: Elaborado pelos autores (2021)

Com base na categorização e na Figura 3, obtida no IRaMuTeQ, é possível identificar 3 grandes características. Na primeira, o termo 'ensino' se sobressai nessa discussão sobre o contexto em que se deram as pesquisas. Ligados a esse termo, com mais proximidade, estão: 'aprendizagem', 'aluno', 'professor' e 'Matemática', o que evidencia uma preocupação do pesquisador em descrever como se dão as relações professor-aluno e aluno-material. Essa proposição pode ser observada na fala de Calheiros [T04], onde se observou que os elementos que constituíram o ambiente virtual proposto no Google Classroom, incentivaram a interação e discussões entre os estudantes, tornando o ensino e a aprendizagem do conteúdo trabalhado mais eficaz e proveitoso. Tomazi [T15] corrobora com essa fala ao afirmar que a utilização da plataforma Khan Academy foi benéfica para o processo de ensino-aprendizagem da Matemática, pois levou o estudante a se interessar pela disciplina.

$\mathrm{Na}$ segunda, por outro lado, é possível observar que os termos 'estudante', 'conteúdo', 'aula' e 'curso', remetem à necessidade de ampliar a discussão com respeito à interação do estudante com os recursos tecnológicos utilizados no AVA. Nesse V. $19 \mathrm{~N}^{\mathrm{o}} 2$, Dezembro, 2021 
sentido, Romanello [T17] afirma que a utilização de recursos digitais no AVA desenvolvido, possibilitou a interação do estudante com o conteúdo proposto, ao fazer a generalização dos conceitos através de gráficos e tabelas no software utilizado na pesquisa. Já numa perspectiva de personalizar o ensino da Matemática, Xoteslem [T14] conclui que a utilização da plataforma Khan Academy fez com que o estudante tivesse maior autonomia e criticidade, o que o tornou mais motivado a aplicar os conceitos matemáticos.

Por fim, na terceira característica, os termos 'Matemática', 'trigonometria', 'geometria', 'estatística' e 'financeiro', ressaltam a discussão que é levantada em torno de certos conteúdos de Matemática, onde se ressalta a utilização de tecnologias como uma metodologia que venha a apoiar o ensino desses conceitos. Nesse cenário, Tenório [T06] investigou por meio de questionários, a compreensão dos estudantes no ensino de probabilidade e estatística frente a utilização de recursos digitais, constatando que a gamificação influenciou diretamente no processo. Santos [T08] aponta que a utilização de vídeo-aulas para o ensino de trigonometria, flexibilizou o tempo de sala de aula e proporcionou mais tempo na discussão do conteúdo.

QP2: Quais as tecnologias digitais utilizadas?

Quanto aos recursos digitais utilizados no desenvolvimento dos trabalhos, pode-se observar uma variedade de tecnologias. A Figura 4 apresenta a análise lexicográfica que identifica a frequência das palavras, separadas em três categorias.

\begin{tabular}{l|r}
\multicolumn{1}{|c}{ Forma } & Freq. \\
\hline moodle & 7 \\
\hline geogebra & 5 \\
\hline classroom & 3 \\
\hline whatsapp & 2 \\
\hline khan_academy & 2 \\
\hline winplot & 1 \\
\hline simulações_ludoteca & 1 \\
\hline power_point & 1 \\
\hline massive_online_open_courses & 1 \\
\hline hangouts & 1 \\
\hline google_formulários & 1 \\
\hline gmail & 1 \\
\hline facebook & 1 \\
\hline explorador_gráfico_de_funções & 1 \\
\hline eclass & 1 \\
\hline círculo_unitário_trigonométrico & 1 \\
\hline coursify_me & 1 \\
\hline aplicativo_matemática & 1 \\
\hline
\end{tabular}

Figura 4 - Análise de Matriz no IRaMuTeQ - forma e frequência: tecnologias digitais utilizadas.

Fonte: Elaborado pelos autores (2021)

$\mathrm{Na}$ primeira categoria ressalta-se as tecnologias digitais que foram utilizadas para a implementação de um Ambiente Virtual de Aprendizagem: MOODLE; Massive Online Open Courses (MOOC); Google Classroom; Plataforma Coursify.me; Whatsapp; Facebook; eClass; Hangouts; Khan Academy.

A segunda reúne os recursos digitais, bem como softwares ou aplicativos, que foram empregados no ensino de conteúdos de Matemática: GeoGebra; Plataforma Khan Academy; Simulações ludoteca; Explorador gráfico de funções; Círculo Unitário Trigonométrico; Winplot; Aplicativo Matemática; Powerpoint. 
Por fim, na terceira categoria aquelas tecnologias digitais utilizadas como um meio para sanar dúvidas dos participantes e promover a interatividade entre eles e o pesquisador: Whatsapp, Google Formulários e o próprio fórum de alguns dos AVA, como o Classroom, Moodle e Hangouts.

Questão 3: Quais as metodologias adotadas?

O objetivo desta questão de pesquisa é identificar as metodologias empregadas no desenvolvimento das pesquisas. As categorias utilizadas classificaram os trabalhos quanto às pesquisa qualitativa de: estudo de caso [T01, T03, T04, T09, T14, T19], pesquisa ação [T13], pesquisa participante [T02, T05, T07, T08, T10, T17, T18, T20]. E as pesquisas quali-quantitativas de: estudo de caso [T06, T11] e pesquisa participante [T15].

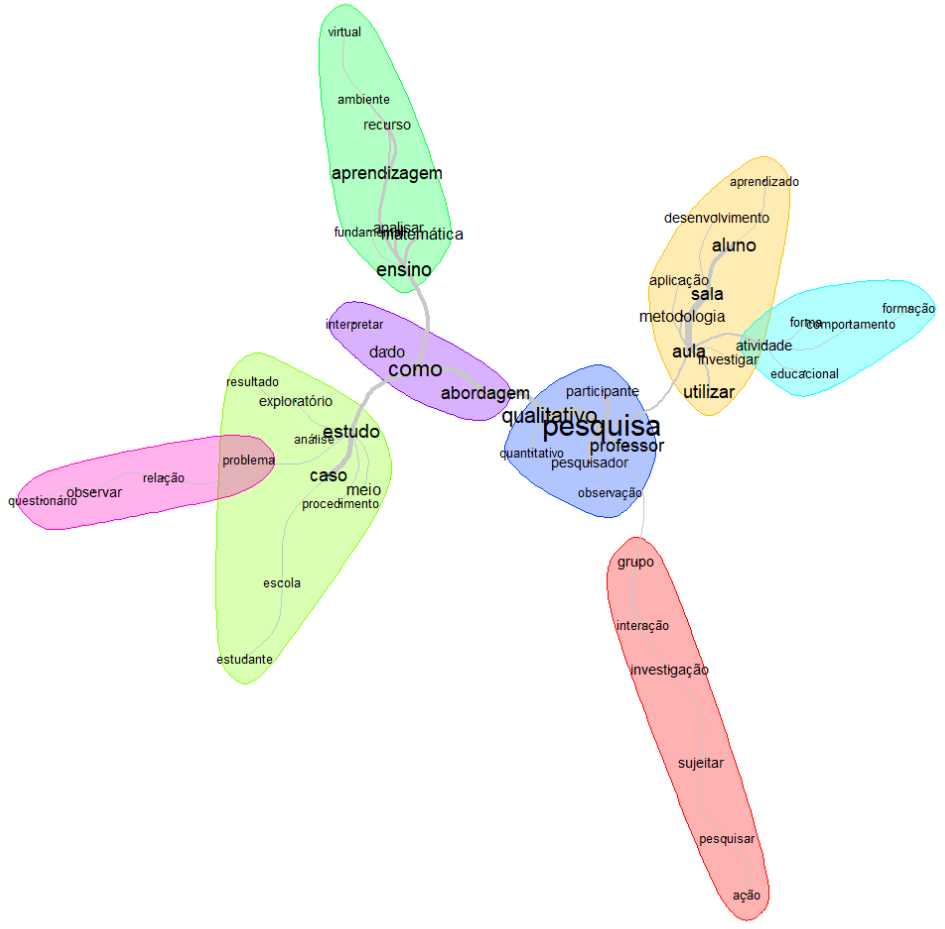

Figura 5 - Análise de Similitude: metodologias adotadas nos trabalhos.

Fonte: Elaborado pelos autores (2021)

Em sua maioria, os trabalhos possuíam cunho qualitativo, com enfoque na pesquisa participante e no estudo de caso. Ressalta-se na Figura 5, os termos 'sala de aula', 'investigar', 'interação' e 'interpretar', estes são abordados principalmente nos trabalhos participativos, pois entende-se que nesse contexto o pesquisador, muitas vezes também é o professor da turma em que está sendo desenvolvida a pesquisa, havendo uma maior interação do professor com o estudante. Saiol [T10] corrobora com essa fala, ao afirmar que se adotou a pesquisa do tipo qualitativa participante, ao assumir ser integrante do público da pesquisa, por ser professora da turma. Malta [T02] enfatiza que a utilização dessa metodologia, aprofunda a investigação e a análise dos resultados, ao mesmo tempo que proporciona a interação, a interdependência e a responsabilidade individual dos participantes. A ação do professor como pesquisador em sala de aula é evidenciada na pesquisa de Felcher [T13], onde se identifica professor e aluno em estreita relação em busca da realização das atividades propostas.

Outra vertente da pesquisa qualitativa utilizada é o estudo de caso, compreendendo também os termos 'exploratório', 'procedimento', 'observar', 'meio' e 
'relação'. Entendendo-se que nesse tipo de pesquisa o caráter exploratório e reflexivo do pesquisador é a chave central desse tipo de metodologia. Neste sentido, a pesquisa de Reinheimer [T01] teve o propósito de interpretar e entender os comportamentos dos estudantes envolvidos com as atividades propostas no AVA. Onde o objetivo não era medir esses comportamentos, mas sim analisá-los e compreendê-los. A metodologia utilizada por Calheiros [T04] investigou o aprendizado dos estudantes em geometria, através da interação deles em um grupo de estudos.

Houveram ainda três pesquisas multimetodológicas de caráter tanto qualitativo quanto quantitativo. Tenório [T06] desenvolveu uma pesquisa caracterizada pela padronização da coleta dos dados, bem como a utilização de questionários e de observação sistemática. Both [T11] utilizou a análise de erros de forma a fundamentar seu estudo. A análise e construção das hipóteses a respeito do desempenho dos estudantes no ensino da matemática descrita por Tomazzi [T15], se deu através de registros e observações feitas na Plataforma Khan Academy.

\section{Ameaças à validade do estudo}

Para evitar ameaças à validade do mapeamento, alguns procedimentos foram seguidos: as questões de pesquisa e os critérios de inclusão e exclusão foram definidos antes do início da busca. Considerando que a busca por trabalhos foi realizada de forma automática utilizando os algoritmos de busca da base escolhida, pode-se ter perdido algum trabalho relevante.

\section{Conclusões}

Neste artigo foi apresentado um panorama das pesquisas sobre o Ensino de Matemática em Ambientes Virtuais de Aprendizagem, no recorte temporal de 2016 a 2020. Para tal, foi conduzido um mapeamento sistemático da literatura, tendo como resultado 20 publicações selecionadas na base de dados BDTD.

Os trabalhos selecionados foram analisados sob a ótica da Análise Textual do Discurso de (MORAES e GALIAZZI, 2006; 2016), de acordo com as etapas de unitarização, categorização e reunião das unidades de significado semelhantes.

Assim, a análise de similitudes textual mostrou que na categorização quanto ao contexto e resultados dos trabalhos selecionados, 14 deles têm suas pesquisas direcionadas para o Ensino básico, 4 para o Ensino superior e 2 para formação continuada. Além do mais, a análise também identificou a preferência de certos conteúdos de matemática, como: trigonometria, geometria, estatística e matemática financeira. Também foi possível mostrar que entre as metodologias adotadas destacam-se a pesquisa qualitativa e quanti-qualitativas com foco no estudo de caso, a pesquisa participante e pesquisa-ação.

Com análise lexicográfica foi possível categorizar as TICs mais utilizadas em três grande grupos, a saber: Ambientes virtuais de aprendizagem, softwares e aplicativos e os ambientes de interatividades como fóruns de discussão, whatsapp, hangout, etc. Vale comentar que este mapeamento sistemático apontou a não observância de trabalhos comparativos entre contextos e metodologias de pesquisa.

Como pesquisas futuras, objetiva-se ampliar o recorte temporal, bem como incluir outras bases de dados para busca no intuito de aumentar o escopo da seleção de produções acadêmicas.

\section{Agradecimentos}

O presente trabalho foi realizado com apoio da Coordenação de Aperfeiçoamento de Pessoal de Nível Superior - Brasil (CAPES) e da Fundação de Amparo à Pesquisa do Estado do Rio Grande do Sul (FAPERGS). 


\section{Referências Bibliográficas}

AMARAL, Priscylla Dietz Ferreira; SABOTA, Barbra. Powtoon: análise do aplicativo web e seu potencial mediador na aprendizagem. Revista Tecnologia e Sociedade, v. 13, n. 28, p. 72-89, 2017.

BRASIL. Ministério da Educação. Parâmetros Curriculares Nacionais, Parte III, Ciências da Natureza, Matemática e suas Tecnologias. Brasília, 2002.

CHICON, Patricia Mariotto Mozzaquatro; PASCHOAL, Leo Natan; FRANTZ, Fabricia Carneiro Roos. Indicadores de Evasão em Ambientes Virtuais de Aprendizagem no contexto da Educação a Distância: Um Mapeamento Sistemático. RENOTE - Revista Novas Tecnologias na Educação, v. 18, n. 2, p. 111-120, 2020.

COSTA, Angelo Brandelli; ZOLTOWSKI; Ana Paula Couto. Como escrever um artigo de revisão sistemática. In: KOLLER, S. H.; COUTO, M. C. P. de P.; HOHENDORFF, J. V. (Org.). Manual de Produção Científica. Porto Alegre: Penso, 2014, p. 55-70.

DICKEL, Marlei Tais; NOTARE, Márcia Rodrigues. Isometrias e Geogebra: o papel do arrastar na construção de conceitos. RENOTE - Revista Novas Tecnologias na Educação, v. 16, n. 1, 2018.

KITCHENHAM, Barbara. et al. Guidelines for performing systematic literature reviews in software engineering. In: Technical report, Ver. 2.3 EBSE Technical Report. EBSE. 2007.

MORAES, Roque; GALIAZZI, Maria do Carmo. Análise Textual Discursiva. 3 ed. ampliada e revisada. Ijuí: Ed. Unijuí, 2016.

MORAES, Roque; GALIAZZI, Maria do Carmo. Análise textual discursiva: processo reconstrutivo de múltiplas faces. Ciência \& Educação, v. 12, n. 1, p. 117-128, 2006.

MORAES, Roque. Uma tempestade de luz: a compreensão possibilitada pela análise textual discursiva. Ciência \& Educação, v. 9, n. 2, p. 191-211, 2003.

RATINAUD, Pierre. IRaMuTeQ: Interface de R pour les Analyses Multidimensionnelles de Textes et de Questionnaires [software computacional]. 2012. Disponível em: $<\mathrm{http}: / / \mathrm{www}$.iramuteq.org $>$.

TEIXEIRA, Odiméia. A Base de Conhecimentos para o ensino da Metodologia da Resolução de Problemas: uma análise a partir de formadores de professores de Matemática. 2020. Dissertação (Mestrado em Ensino de Ciências e Educação Matemática) - Universidade Estadual de Ponta Grossa, Ponta Grossa, 2020. 